\title{
Comparative Susceptibility of Kudzu Accessions from the Southeastern United States to Infection by Phakopsora pachyrhizi
}

\author{
M. R. Bonde and S. E. Nester, USDA, ARS, Foreign Disease-Weed Science Research Unit, 1301 Ditto Ave., Fort \\ Detrick, MD 21702; W. F. Moore, Department of Entomology and Plant Pathology, Box 9655, Dorman Hall, Mis- \\ sissippi State University, Mississippi State 39762; and T. W. Allen, Delta Research and Extension Center, Missis- \\ sippi State University, 82 Stoneville Road, Stoneville 38776
}

\begin{abstract}
Bonde, M. R., Nester, S. E., Moore, W. F., and Allen, T. W. 2009. Comparative susceptibility of kudzu accessions from the southeastern United States to infection by Phakopsora pachyrhizi. Plant Dis. 93:593-598.

Soybean rust, caused by Phakopsora pachyrhizi, was first discovered in the continental United States in the fall of 2004. The potential for economic loss in the United States hinges largely on whether or not the pathogen can survive winters in the absence of soybean. Kudzu (Pueraria lobata) is known to be a host for P. pachyrhizi in Asia and South America and is widely distributed in the southern United States. This study examined reactions of kudzu collected from several areas of the southeastern United States to three isolates of $P$. pachyrhizi, one each from Alabama, Louisiana, and Brazil. Susceptible tan (TAN) lesions, resistant reddish-brown (RB) lesions, and immune (IM) response, previously described on soybean, were produced on kudzu based on the evaluation of 125 plants. However, in contrast to soybean, the RB response on kudzu was common, with approximately $50 \%$ frequency. IM responses to at least one isolate were observed on five individual plants, and two plants were immune to all three pathogen isolates used in the test. TAN lesions averaged 3.2 uredinia per lesion with an average diameter per uredinium of $121 \mu \mathrm{m}$. In contrast, RB lesions had an average of 0.3 uredinia per lesion with an average uredinial diameter of $77 \mu \mathrm{m}$. In 25 of $39(64 \%)$ instances in which multiple plants were tested from a site, each reacted the same to the individual pathogen isolates. This suggested a tendency for plants at specific sites to be genetically identical with respect to rust reaction. Only 19 of $125(15 \%)$ individual plants produced a different reaction to one isolate than to the other two isolates. When four kudzu plants previously shown to produce only TAN lesions to $P$. pachyrhizi isolates Alabama 04-1, Brazil 01-1, and Louisiana 04-1 were inoculated with eight additional isolates from several areas of the world, all 11 isolates produced only TAN lesions. Likewise, when five other plants previously shown to produce only RB lesions when inoculated with the three isolates were inoculated with the 11 isolates, all produced only RB lesions. These results suggest that susceptibility or resistance to $P$. pachyrhizi in individual kudzu plants often is broad, extending over a wide range of $P$. pachyrhizi isolates.
\end{abstract}

Soybean rust, incited by Phakopsora pachyrhizi Syd., was discovered for the first time in the continental United States in 2004 (11), but as of 2008 it has caused little damage. Research on the disease at the United States Department of Agriculture (USDA), Foreign Disease-Weed Science Research Unit began in 1972, and

Corresponding author: M. R. Bonde

E-mail: morris.bonde@ars.usda.gov

The use of trade, firm, or corporation names in this publication is for the information and convenience of the reader. Such use does not constitute an official endorsement or approval by the U.S. Department of Agriculture or the Agricultural Research Service of any product or service to the exclusion of others that may be suitable.

Accepted for publication 11 February 2009.

doi:10.1094/PDIS-93-6-0593

This article is in the public domain and not copyrightable. It may be freely reprinted with customary crediting of the source. The American Phytopathological Society, 2009. until recently it was conducted only in the USDA Biosafety Level-3 plant disease containment facility at Fort Detrick, MD (9) or in foreign countries where the disease existed in the field (5).

During early studies at USDA, Melching et al. (8) and Bromfield (5) recognized the importance of legumes, other than soybean, as a possible bridge on which $P$. pachyrhizi could survive winters in certain areas of the United States. Bromfield (5), and more recently Bonde et al. (3), suggested that the prolific leguminous weed kudzu (Pueraria montana (Lour.) Merr. var. lobata (Willd.) Sanjappa \& Pradeep), in areas where leaves did not freeze, might be that bridge. Bonde et al. (3) showed that at least some kudzu accessions from the United States were highly susceptible to soybean rust and produced copious amounts of urediniospores.

Kudzu, a perennial semi-woody, climbing vine, is a leguminous plant belonging to the tribe Phaseoleae Benth., subtribe Glycininae Benth. (according to International Legume Database \& Information
Service Web Site: http://www.ildis.org/ LegumeWeb), and was first introduced into the United States in 1876 as an ornamental plant (4). Its nearest relative in the continental United States is soybean (Glycine $\max$ (L.) Merr.) (4). P. phaseoloides (Roxb.) Benth., although a closer relative, is established in Hawaii and Puerto Rico, and not in the continental United States. By the 1930s and 1940s, kudzu became highly promoted by agriculturalists in Alabama, Georgia, and Mississippi as a means of decreasing soil erosion (4). The Federal Soil Erosion Service eventually paid farmers to plant kudzu on more than 1.2 million acres, and kudzu became promoted as a drought-resistant, high-nitrogen forage crop. But kudzu had several major problems, including the difficulty that farmers had in baling the hay and the tendency for the crop to grow so rapidly and extensively that it covered all other vegetation. As a result, in 1998 Congress placed kudzu on the federal list of noxious weeds. Today, it is estimated to infest between 2 and 7 million acres, primarily in the southeastern United States (4).

The research presented here expands upon a previous study in which we compared several leguminous species as hosts for $P$. pachyrhizi (3). Here we compare reactions of 125 kudzu plants, most from Mississippi, to infection by three pathogen isolates, one each from Alabama, Louisiana, and Brazil. The results should help determine the relative frequencies of resistance and susceptibility to $P$. pachyrhizi in kudzu and the possible role this host might play in the over wintering of $P$. pachyrhizi in the southeastern United States.

\section{MATERIALS AND METHODS}

Pathogen isolates. Three isolates of $P$. pachyrhizi were used to inoculate each kudzu plant in the study. Brazil 01-1 was a field collection of urediniospores collected in Brazil in 2001 by J. T. Yorinori, EMBRAPA SOJA, Londrina, Brazil, and sent to R. Frederick at the FDWSRU on infected leaves under an appropriate APHIS permit. Alabama 04-1 was collected in 2004 by R. D. Frederick and M. R. Bonde in Mobile County, AL, and Louisiana 04-1 was collected in 2004 by R. Schneider (Louisiana State University) from the Ben Hur location, site of the first discovery of soybean rust in the continental United 
States, Baton Rouge, LA. The Alabama and Louisiana isolates, following collection, were purified by repeated serial passage as single pustules on soybean cv. Williams prior to this study.

In an experiment to better understand the breadth of resistance, or susceptibility, to soybean rust in individual kudzu plants, eight $P$. pachyrhizi isolates were used to inoculate a set of four plants that previously had produced only tan (TAN) lesions with Alabama 04-1, Brazil 01-1, and Louisiana 04-1. A second set of four plants that had produced only reddish-brown (RB) lesions with the same three isolates likewise was inoculated with the eight additional $P$. pachyrhizi isolates. Due to the death of one plant during the experiment, a replacement plant was added to the experiment and inoculated with some of the isolates.

All isolates were maintained on cv. Williams soybean. Periodically, urediniospores were collected from infected plants by means of a vacuum spore collection device (7) and stored in a liquid nitrogen refrigerator for later use in experiments or for long-term preservation. All pathogen isolates used in this study currently are being maintained in liquid nitrogen storage at FDWSRU.

Kudzu accessions. Pods from kudzu plants at each of 56 geographically distinct locations in the southeastern United States (Table 1) were collected and sent to the laboratory at Fort Detrick, where seeds were removed from the pods. Twenty-two collections were made in 2005 and are referred to in this publication as "Set \#1", and 34 were made in 2006 and referred to as "Set \#2". Geographic coordinates were recorded for all 51 locations in Mississippi.

Kudzu seeds were soaked in concentrated sulfuric acid for $2 \mathrm{~h}$, rinsed 3 to 4 min with tap water, and incubated on wet filter paper in petri dishes at $30^{\circ} \mathrm{C}$ (13). Following germination, seedlings were transplanted into soil in 10.2-cm-diameter clay pots and placed in a greenhouse for approximately 3 months to allow sufficient plant growth for use in experiments.

Inoculation and maintenance of plants. One day prior to inoculation, urediniospores of the three $P$. pachyrhizi isolates were removed separately from liquid nitrogen storage, heat shocked while dry for $5 \mathrm{~min}$ at $40^{\circ} \mathrm{C}$, and then hydrated for $16 \mathrm{~h}$ at $100 \% \mathrm{RH}$ by placement over water in a closed glass petri dish at room temperature (2). Hydrated urediniospores were suspended in distilled water containing one drop of Tween 20 per $100 \mathrm{ml}$, enumerated by means of a hemacytometer, and adjusted to a final concentration of 2.5 to 3.5 $\times 10^{4}$ urediniospores $/ \mathrm{ml}$. Each of three trifoliolate leaves on each plant in an experiment was inoculated by painting with a suspension of urediniospores of a single isolate using a 1-in.-wide bristle brush.
Table 1. Lesion types for specific kudzu (Pueraria montana var. lobata) plants grown from seeds obtained from 56 field locations in southeastern United States inoculated separately with three isolates of Phakopsora pachyrhizi $i^{\mathrm{a}}$

\begin{tabular}{|c|c|c|c|c|}
\hline \multirow[b]{2}{*}{ Year/location ${ }^{c}$} & \multirow[b]{2}{*}{ Plant identity } & \multicolumn{3}{|c|}{ Pathogen isolate $^{b}$} \\
\hline & & Alabama 04-1 & Brazil 01-1 & Louisiana 04-1 \\
\hline \multicolumn{5}{|l|}{2005} \\
\hline 1 & $A^{d}$ & $\mathrm{RB}^{\mathrm{e}}$ & $\mathrm{RB}$ & TAN $^{f}$ \\
\hline 1 & B & TAN & TAN & TAN \\
\hline 2 & A & $\mathrm{RB}$ & $\mathrm{RB}$ & TAN \\
\hline 3 & A & TAN & TAN & TAN \\
\hline 3 & B & TAN & TAN & TAN \\
\hline 3 & $\mathrm{C}$ & TAN & TAN & TAN \\
\hline 4 & A & $\mathrm{RB}$ & TAN & TAN \\
\hline 5 & A & TAN & TAN & TAN \\
\hline 5 & B & TAN & TAN & TAN \\
\hline 5 & $\mathrm{C}$ & TAN & TAN & TAN \\
\hline 6 & A & $\mathrm{RB}$ & $\mathrm{RB}$ & $\mathrm{RB}$ \\
\hline 6 & B & $\mathrm{RB}$ & $\mathrm{RB}$ & $\mathrm{RB}$ \\
\hline 7 & A & $\mathrm{RB}$ & $\mathrm{RB}$ & TAN \\
\hline 7 & B & $\mathrm{RB}$ & $\mathrm{TAN} \mathrm{RB}^{\mathrm{g}}$ & TAN \\
\hline 8 & A & TAN & TAN & TAN \\
\hline 8 & B & TAN & TAN & TAN \\
\hline 9 & A & $\mathrm{RB}$ & $\mathrm{RB}$ & $\mathrm{RB}$ \\
\hline 10 & A & TAN & TAN & TAN \\
\hline 10 & B & TAN & TAN & TAN \\
\hline 11 & A & TAN & TAN & TAN \\
\hline 11 & B & TAN & TAN & TAN \\
\hline 12 & A & $\mathrm{RB}$ & $\mathrm{RB}$ & $\mathrm{RB}$ \\
\hline 12 & B & $\mathrm{RB}$ & $\mathrm{RB}$ & $\mathrm{RB}$ \\
\hline 12 & C & $\mathrm{RB}$ & $\mathrm{RB}$ & $\mathrm{RB}$ \\
\hline 13 & A & TAN & TAN & TAN \\
\hline 13 & B & TAN & TAN & TAN \\
\hline 13 & $\mathrm{C}$ & TAN & $-^{\mathrm{h}}$ & TAN \\
\hline 14 & A & TAN & TAN & TAN \\
\hline 14 & B & $\mathrm{RB}$ & $\mathrm{RB}$ & $\mathrm{RB}$ \\
\hline 14 & $\mathrm{C}$ & $\mathrm{RB}$ & $\mathrm{RB}$ & $\mathrm{RB}$ \\
\hline 14 & $\mathrm{D}$ & $\mathrm{RB}$ & $\mathrm{RB}$ & $\mathrm{RB}$ \\
\hline 14 & E & $\mathrm{RB}$ & $\mathrm{RB}$ & $\mathrm{RB}$ \\
\hline 14 & $\mathrm{~F}$ & TAN & TAN & TAN \\
\hline 14 & G & TAN & TAN & TAN \\
\hline 15 & A & TAN & TAN & TAN \\
\hline 16 & A & $\mathrm{RB}$ & $\mathrm{RB}$ & $\mathrm{RB}$ \\
\hline 16 & B & $\mathrm{RB}$ & TAN/RB & $\mathrm{RB}$ \\
\hline 16 & $\mathrm{C}$ & $\mathrm{RB}(\mathrm{IR})^{\mathrm{i}}$ & RB (IR) & RB (IR) \\
\hline 17 & A & TAN & TAN & TAN \\
\hline 17 & B & $\mathrm{RB}$ & $\mathrm{RB}$ & $\mathrm{RB}$ \\
\hline 18 & A & TAN & TAN & TAN \\
\hline 18 & B & TAN & TAN & TAN \\
\hline 19 & A & TAN & TAN & TAN \\
\hline 20 & B & TAN & TAN & TAN \\
\hline 21 & B & $\mathrm{RB}$ & $\mathrm{RB}$ & $\mathrm{RB}$ \\
\hline 22 & $\mathrm{~B}$ & $\mathrm{RB}$ & $\mathrm{RB}$ & $\mathrm{RB}$ \\
\hline \multicolumn{5}{|l|}{2006} \\
\hline 23 & A & $\mathrm{RB}$ & $\mathrm{RB}$ & $\mathrm{RB}$ \\
\hline 23 & B & $\mathrm{RB}$ & $\mathrm{RB}$ & $\mathrm{RB}$ \\
\hline 23 & $\mathrm{C}$ & $\mathrm{RB}$ & $\mathrm{RB}$ & $\mathrm{RB}$ \\
\hline 24 & A & $\mathrm{RB}$ & $\mathrm{RB}$ & $\mathrm{RB}$ \\
\hline 24 & B & $\mathrm{RB}$ & $\mathrm{RB}$ & TAN \\
\hline \multirow[t]{2}{*}{24} & C & TAN & TAN & TAN \\
\hline & & & \multicolumn{2}{|c|}{ (Continued on next page } \\
\hline
\end{tabular}

a Kudzu plants were inoculated by painting each of three leaves separately with a urediniospore suspension at 2.5 to $3.5 \times 10^{4}$ urediniospores $/ \mathrm{ml}$ distilled water containing 1 drop Tween 20 per $100 \mathrm{ml}$. Inoculated plants were incubated overnight in dew chambers at $20^{\circ} \mathrm{C}$, removed from the chambers the next morning, allowed to dry, and then placed in the greenhouse at 20 to $25^{\circ} \mathrm{C}$ for disease development. Two weeks after inoculation, plants were examined for symptoms.

b Alabama 04-1 is a purified isolate from a field collection made in Alabama in 2004; Brazil 01-1 is a nonpurified field isolate from Londrina, Brazil; and Louisiana 04-1 is a purified isolate from a field collection from the Ben Hur Field Station, LA, initial site of discovery of soybean rust in the United States in 2004.

c Plant locations 1 through 17 and 23 through 56 were in Mississippi. Plant locations 18 through 20 were in Louisiana, 21 in Kentucky, and 22 in North Carolina.

d Each plant, with letter designation, is from the location immediately to the left.

e $\mathrm{RB}=$ reddish-brown lesions, characterized by few or no urediniospores.

f TAN $=$ tan-colored lesions, characterized by numerous tan-colored urediniospores.

$\mathrm{g}$ TAN $\backslash \mathrm{RB}=$ a mixture of TAN and RB lesions on the inoculated leaf.

h - Indicates missing data.

${ }^{\mathrm{i}} \mathrm{RB}$ (IR) indicates reddish-brown lesions in first experiment and no symptoms in second experiment. 
Table 1. (Continued from previous page)

\begin{tabular}{|c|c|c|c|c|}
\hline \multirow[b]{2}{*}{ Year/location $^{c}$} & \multirow[b]{2}{*}{ Plant identity } & \multicolumn{3}{|c|}{ Pathogen isolate $^{b}$} \\
\hline & & Alabama 04-1 & Brazil 01-1 & Louisiana 04-1 \\
\hline 25 & A & $\mathrm{RB}$ & RB & $\mathrm{RB}$ \\
\hline 26 & A & $\mathrm{RB}$ & RB & $\mathrm{RB}$ \\
\hline 27 & A & $\mathrm{RB}$ & RB & $\mathrm{RB}$ \\
\hline 28 & A & RB & RB & RB \\
\hline 28 & B & $\mathrm{RB}$ & $\mathrm{RB}$ & $\mathrm{RB}$ \\
\hline 28 & $\mathrm{C}$ & $\mathrm{RB}$ & RB & RB \\
\hline 29 & A & TAN & TAN & TAN \\
\hline 29 & B & TAN & TAN & TAN \\
\hline 29 & $\mathrm{C}$ & TAN & TAN & TAN \\
\hline 30 & A & $\mathrm{RB}$ & $\mathrm{RB}$ & RB \\
\hline 30 & $\mathrm{~B}$ & $\mathrm{RB}$ & $\mathrm{RB}$ & $\mathrm{RB}$ \\
\hline 31 & A & TAN & TAN & TAN \\
\hline 32 & A & RB & $\mathrm{RB}$ & $\mathrm{RB}$ \\
\hline 32 & B & $\mathrm{RB}$ & $\mathrm{RB}$ & $\mathrm{RB}$ \\
\hline 32 & $\mathrm{C}$ & TAN & TAN & TAN \\
\hline 33 & A & TAN & TAN & TAN \\
\hline 33 & B & TAN & TAN & TAN \\
\hline 33 & $\mathrm{C}$ & TAN & TAN & TAN \\
\hline 34 & A & TAN & TAN & TAN \\
\hline 34 & B & TAN & TAN & TAN \\
\hline 34 & $\mathrm{C}$ & TAN & TAN & TAN \\
\hline 35 & A & $\mathrm{RB}$ & $\mathrm{RB}$ & $\mathrm{RB}$ \\
\hline 35 & B & $\mathrm{RB}$ & $\mathrm{RB}$ & $\mathrm{RB}$ \\
\hline 35 & $\mathrm{C}$ & RB & $\mathrm{RB}$ & $\mathrm{RB}$ \\
\hline 36 & $\mathrm{~A}$ & $\mathrm{RB}$ & $\mathrm{RB}$ & $\mathrm{RB}$ \\
\hline 36 & B & $\mathrm{RB}$ & $\mathrm{RB}$ & $\mathrm{RB}$ \\
\hline 36 & $\mathrm{C}$ & $\mathrm{RB}$ & RB & RB \\
\hline 37 & A & $\mathrm{RB}$ & $\mathrm{RB}$ & $\mathrm{RB}$ \\
\hline 38 & A & RB & RB & $\mathrm{RB}$ \\
\hline 39 & A & RB & RB & $\mathrm{RB}$ \\
\hline 40 & A & RB & RB & RB \\
\hline 40 & B & TAN & TAN & TAN \\
\hline 40 & $\mathrm{C}$ & $\mathrm{RB}$ & $\mathrm{RB}$ & $\mathrm{RB}$ \\
\hline 41 & A & RB & RB & $\mathrm{RB}$ \\
\hline 41 & B & $\mathrm{IM}^{\mathrm{i}}$ & IM & IM \\
\hline 41 & $\mathrm{C}$ & IM & IM & IM \\
\hline 42 & A & $\mathrm{RB}$ & $\mathrm{RB}$ & RB \\
\hline 42 & B & RB & RB & $\mathrm{RB}$ \\
\hline 42 & $\mathrm{C}$ & $\mathrm{RB}$ & $\mathrm{RB}$ & $\mathrm{RB}$ \\
\hline 43 & A & TAN & TAN & TAN \\
\hline 43 & B & TAN & TAN & TAN \\
\hline 43 & $\mathrm{C}$ & TAN & TAN & TAN \\
\hline 44 & A & $\mathrm{RB}$ & RB & RB \\
\hline 44 & B & $\mathrm{RB}$ & $\mathrm{RB}$ & $\mathrm{RB}$ \\
\hline 44 & $\mathrm{C}$ & $\mathrm{RB}$ & $\mathrm{RB}$ & $\mathrm{RB}$ \\
\hline 45 & A & $\mathrm{RB}$ & TAN & TAN \\
\hline 45 & B & $\mathrm{RB}$ & TAN & TAN \\
\hline 46 & A & TAN & TAN & TAN \\
\hline 46 & B & TAN & TAN & TAN \\
\hline 46 & $\mathrm{C}$ & TAN & TAN & TAN \\
\hline 47 & A & $\mathrm{RB}$ & $\mathrm{RB}$ & $\mathrm{RB}$ \\
\hline 47 & B & RB & $\mathrm{RB}$ & TAN \\
\hline 48 & A & TAN & TAN & TAN \\
\hline 48 & B & TAN & TAN & TAN \\
\hline 49 & A & TAN & TAN & TAN \\
\hline 49 & $\mathrm{~B}$ & TAN & TAN & TAN \\
\hline 49 & $\mathrm{C}$ & TAN & TAN & TAN \\
\hline 50 & A & $\mathrm{RB}$ & $\mathrm{RB}$ & TAN \\
\hline 50 & B & TAN & TAN & TAN \\
\hline 50 & $\mathrm{C}$ & $\mathrm{RB}$ & $\mathrm{RB}$ & TAN \\
\hline 51 & A & TAN & $\mathrm{RB}$ & TAN \\
\hline 52 & A & TAN & TAN & TAN \\
\hline 52 & B & TAN & $\mathrm{RB}$ & TAN \\
\hline 52 & $\mathrm{C}$ & TAN & TAN & TAN \\
\hline 53 & A & IM & TAN & TAN \\
\hline 54 & A & $\mathrm{RB}$ & $\mathrm{RB}$ & $\mathrm{RB}$ \\
\hline 54 & B & $\mathrm{RB}$ & $\mathrm{RB}$ & $\mathrm{RB}$ \\
\hline 55 & A & $\mathrm{RB}$ & $\mathrm{RB}$ & TAN \\
\hline 55 & B & TAN & TAN & TAN \\
\hline 55 & $\mathrm{C}$ & $\mathrm{RB}$ & $\mathrm{RB}$ & TAN \\
\hline 56 & A & TAN & TAN & TAN \\
\hline 56 & $\mathrm{~B}$ & $\mathrm{IM}$ & TAN & TAN \\
\hline 56 & $\mathrm{C}$ & IM & $\mathrm{RB}$ & TAN \\
\hline Soybean (control) & A-K & TAN & TAN & TAN \\
\hline
\end{tabular}

Leaves of soybean plants of the susceptible cv. Williams were inoculated similarly with each of the three pathogen isolates to serve as controls. Following inoculation, all plants were incubated overnight in dew chambers at $20^{\circ} \mathrm{C}$, removed from the chambers, allowed to dry, and then placed in a greenhouse at 20 to $25^{\circ} \mathrm{C}$ for disease development.

After the first experiment was completed, the plants were allowed to regrow until sufficient new leaves were present for repeating the experiment using the same pathogen isolates.

Lesion type, density, and sporulation ratings. Two weeks after inoculation, data were collected for lesion types, relative lesion densities, and proportion of lesions that had sporulating uredinia. Lesion reactions, recorded 2 weeks after inoculation, were classified as TAN, RB, or IM, as described on soybean $(2,6)$. TAN indicated lesions were tan-colored, RB that lesions were reddish to dark chocolate brown, and IM that there were no apparent symptoms. TAN and RB designations were assigned solely on lesion color; however, TAN reactions usually had much higher proportions of lesions with sporulating uredinia than $\mathrm{RB}$ reactions. Mixtures of TAN and RB lesions were noted. Photographs at $\times 7$ and $\times 25$ were taken of the surface of leaves with a Nikon Digital Sight DS-L1 digital camera mounted on an Olympus SZX12 dissecting microscope at the time of scoring.

Lesion densities were rated on a 5-point scale as described (3) in which $1=$ no lesions, $2=\mathrm{a}$ few lesions, $3=\mathrm{a}$ light lesion density, 4 = a moderate lesion density, and $5=$ a heavy lesion density, the last comparable to that of infection on the soybean control included in each experiment. The proportion of lesions with sporulating uredinia (referred to as sporulating lesions) for each of three pathogen isolates per plant was rated from 0 to 5 , where $0=$ no lesions sporulating, $1=20 \%$ lesions sporulating, $2=40 \%$ lesions sporulating, $3=$ $60 \%$ lesions sporulating, $4=80 \%$ lesions sporulating, and $5=100 \%$ lesions with uredinia sporulating (10).

Number of uredinia per lesion and uredinium diameters. For kudzu Set \#1, after collecting data for lesion density, sporulation, and reaction type, selected leaflets with symptoms were excised from the plants and fixed in Farmer's solution (2:1 absolute ethanol:acetic acid) for at least $24 \mathrm{~h} \mathrm{(1).} \mathrm{The} \mathrm{leaflets} \mathrm{then} \mathrm{were} \mathrm{sub-}$ merged for $24 \mathrm{~h}$ in lactophenol to remove pigments and stained overnight in lactophenol containing $0.1 \%$ cotton blue (1). Excess stain was removed from the surface of the leaflets by rinsing them in clear lactophenol.

The stained leaflets were mounted by placing them abaxial side up on a layer of lactophenol in a plastic petri dish lid, placing drops of lactophenol on the surface of 
the leaflets, and inserting a petri dish bottom into the top so that the leaflets were sandwiched between two pieces of clear plastic. They were examined as whole-leaf mounts at $\times 15$ magnification to determine numbers of uredinia per lesion and at $\times 90$ magnification to measure uredinium diameters by means of an ocular micrometer.

Data analyses. Each leaf (consisting of three leaflets) was treated as a separate unit and represented a pathogen isolate/plant combination when determining lesion densities and sporulation ratings. The mean lesion density rating was calculated for all TAN and for all RB reactions, respectively, for each pathogen isolate in each of the two experiments, and results of the three isolates were averaged within experiments. Similarly, the mean sporulation rating was calculated for all TAN reactions and all $\mathrm{RB}$ reactions, respectively, for each pathogen isolate in each of the two experiments, and results of the three isolates were averaged within experiments.

In a single experiment, the mean number of uredinia per lesion $(n=25)$ for each leaf on each of $27 \mathrm{kudzu}$ plants (from locations 1 to 13 of Set \#1) was determined, and the data within isolates were averaged for TAN and RB lesions, respectively (Table 2).

Similarly, the mean uredinium diameter ( $n=25$, fewer if 25 not available) for each pathogen isolate/plant combination was determined, and data for all TAN and for all RB lesions, respectively, were averaged within isolates (Table 2).

\section{RESULTS}

Lesion type, density, and proportion of lesions with sporulating uredinia. Each of the 125 plants, from a total of 56 locations, 51 of which were in Mississippi (Table 1), produced the same reaction type in each of the two experiments to the respective $P$. pachyrhizi isolates, confirming reproducibility of results. In the few instances in which symptoms were borderline between TAN and RB, final assignment of reaction type was based on a histological examination of fixed, cleared, and stained leaf tissue. Typical symptoms on living leaves and fungal development within leaves as revealed by histological treatment are shown in Figure 1.

Of the 125 inoculated plants, $19(15 \%)$ developed a different reaction to one isolate as compared to the other two isolates (Table 1). Fifty-four plants produced only TAN lesions, 50 only RB lesions, and two had no symptoms when inoculated with the three pathogen isolates. Two plants (7B and 16B) gave mixtures of TAN and RB lesions when inoculated with isolate Brazil 01-1, which was not unexpected since this isolate is known to be a mixture of "races" (2). When four individual plants (12B, $17 \mathrm{C}, 18 \mathrm{~B}$, and $18 \mathrm{C}$ ) previously shown to produce only TAN lesions to the three isolates were inoculated with eight additional $P$. pachyrhizi isolates, collected from different parts of the world over three decades, each produced only TAN lesions (Table 3). Similarly, when five plants (1B, 14B, 16B, 19A, and 25C), one a replacement partway through the experiment due to death of a plant, that previously had produced only $\mathrm{RB}$ lesions to the three isolates were inoculated with the eight additional isolates, all 11 isolates produced only RB lesions (Table 3). These results show a strong tendency for individual kudzu plants to have resistance or susceptibility to a very broad range of $P$. pachyrhizi isolates.
All of the plants from 25 of 39 (64\%) sites from which multiple plants were tested with Alabama 04-1, Brazil 01-1, and Louisiana 04-1 reacted the same to the respective isolates (Table 1). For example, for location \#12, all three plants produced $\mathrm{RB}$ lesions in response to the three pathogen isolates, and for location \#45, both plants produced RB lesions to Alabama 04-1 and TAN lesions to the other two isolates. The distribution of reaction types associated with field locations was random (Fig. 2).

Average lesion densities always were significantly higher on plants with TAN reactions than on plants with $\mathrm{RB}$ reactions. In experiment $\# 1$, average lesion density ratings $(n=3)$ for the three rust isolates were (mean \pm conf. int., $P=0.05$ ) 4.2 $( \pm 0.1)$ and $3.4( \pm 0.1)$ for plants with TAN and $\mathrm{RB}$ reactions, respectively. In experiment \#2, average lesion density ratings ( $n$ $=3)$ were $4.8( \pm 0.1)$ and $3.9( \pm 0.2)$ for plants with TAN and RB lesions, respectively. In all six instances (includes experiments \#1 and \#2) in which a given isolate was used to inoculate a set of kudzu accessions, ratings for lesion densities were higher for TAN than for RB reactions.

TAN reactions also produced significantly higher proportions of lesions with sporulating uredinia than $\mathrm{RB}$ reactions. TAN reactions almost always were rated 5 (100\% of lesions with sporulating uredinia), and $\mathrm{RB}$ reactions rated 0 to 2 ( 0 to $40 \%$ of lesions with sporulating uredinia). Average sporulation ratings $(n=3)$ for the three rust isolates were $4.9( \pm 0.1)$ and 1.0 $( \pm 0.3)$ for TAN and RB lesions, respectively, in experiment $\# 1$. In experiment \#2 $(n=3)$, they were $4.9( \pm 0.1)$ and $0.8( \pm 0.2)$ for TAN and RB reactions, respectively.

Table 2. Mean number of uredinia per lesion and mean uredinia diameters for isolates Alabama 04-1, Brazil 01-1, and Louisiana 04-1 of Phakopsora pachyrhizi following inoculation of kudzu or soybean plants ${ }^{\mathrm{a}}$

\begin{tabular}{|c|c|c|c|c|c|c|}
\hline \multirow[b]{2}{*}{ Plant/reaction type } & \multicolumn{3}{|c|}{ Mean number of uredinia/lesion ${ }^{b}$} & \multicolumn{3}{|c|}{ Mean uredinia diameter $(\mu \mathrm{m})^{\mathrm{c}}$} \\
\hline & AL04-1 & BZ01-1 & LA04-1 & AL04-1 & BZ01-1 & LA04-1 \\
\hline Kudzu TAN & $\begin{array}{c}2.9 \\
(16) \\
( \pm 0.3)\end{array}$ & $\begin{array}{c}3.2 \\
(16) \\
( \pm 0.2)\end{array}$ & $\begin{array}{c}3.4 \\
(21) \\
( \pm 0.3)\end{array}$ & $\begin{array}{l}122 \\
(16) \\
( \pm 3)\end{array}$ & $\begin{array}{l}124 \\
(16) \\
( \pm 3)\end{array}$ & $\begin{array}{l}116 \\
(21) \\
( \pm 3)\end{array}$ \\
\hline Kudzu RB & $\begin{array}{c}0.4 \\
(11) \\
( \pm 0.3)\end{array}$ & $\begin{array}{c}0.3 \\
(9) \\
( \pm 0.1)\end{array}$ & $\begin{array}{c}0.2 \\
(6) \\
( \pm 0.2)\end{array}$ & $\begin{array}{c}72 \\
(6) \\
( \pm 12)\end{array}$ & $\begin{array}{l}80 \\
(6) \\
( \pm 3)\end{array}$ & $\begin{array}{c}79 \\
(3) \\
( \pm 7)\end{array}$ \\
\hline Soybean TAN & $\begin{array}{c}4.1 \\
(2) \\
( \pm 0.3)\end{array}$ & $\begin{array}{c}4.5 \\
(1) \\
( \pm 0.0)\end{array}$ & $\begin{array}{c}5.4 \\
(2) \\
( \pm 0.0)\end{array}$ & $\begin{array}{l}131 \\
(2) \\
( \pm 0)\end{array}$ & $\begin{array}{c}125 \\
(1) \\
( \pm 0)\end{array}$ & $\begin{array}{l}130 \\
(2) \\
( \pm 8)\end{array}$ \\
\hline
\end{tabular}

a Kudzu and soybean plants were inoculated by painting each of three leaves per plant with a separate urediniospore suspension at 2.5 to $3.5 \times 10^{4}$ urediniospores/ml distilled water containing 1 drop Tween 20 per $100 \mathrm{ml}$. Inoculated plants were incubated overnight in dew chambers at $20^{\circ} \mathrm{C}$, removed from the chambers the following morning, allowed to dry, and then placed in the greenhouse at 20 to $25^{\circ} \mathrm{C}$ for disease development. Two weeks after inoculation, plants were examined for symptoms and leaves collected for histology. Al04-1 = isolate Alabama 04-1, BZ01-1 = isolate Brazil 01-1, and LA04-1 = isolate Louisiana 04-1.

b Mean number of uredinia per lesion was determined for each plant/pathogen isolate combination from 25 randomly selected uredinia; overall means for each specific isolate were determined by averaging data from all plants with TAN or RB reactions, respectively. Upper numbers in parentheses are the numbers of plants developing the specific lesion type, and lower numbers in parentheses one standard error of the means based on variation among plants (in upper parentheses).

c Mean uredinia diameters were based on 25 randomly selected uredinia per plant/pathogen isolate combination, and overall means were determined for each specific pathogen isolate. Upper numbers in parentheses are numbers of plants sampled. Lower numbers in parentheses are one standard error of the means based on variation among plants (upper parentheses). Note that some plants produced no uredinia within RB lesions, and therefore contributed no data toward overall means for uredinia diameters. 
Average numbers of uredinia per lesion and average uredinium diameters. The average numbers of uredinia per lesion and average uredinium diameters for TAN and RB lesions, respectively, for each of the three pathogen isolates on 27 plants (from Set \#1) are presented in Table 2. For example, isolate Alabama 04-1 produced a mean of 2.9 uredinia per lesion on leaves with TAN reactions and 0.4 uredinia per lesion on leaves with RB reactions. Mean uredinia diameters were $122 \mu \mathrm{m}$ for TAN reactions and $72 \mu \mathrm{m}$ for $\mathrm{RB}$ reactions. Furthermore, for all pathogen isolates, 49 of 53 interactions in which TAN lesions were produced had an average of 1.8 or more uredinia per lesion, whereas 24 of 26 interactions in which $\mathrm{RB}$ lesions were produced had an average of 1.0 or fewer uredinia per lesion.

\section{DISCUSSION}

Reaction types produced on kudzu in this study were similar to those previously reported on soybean $(2,5)$, that is TAN, $\mathrm{RB}$, and IM. However, in contrast to soybean, the RB reaction was very common. In a total of 374 interactions between host and pathogen, 177 (47\%) were RB. IM reactions to at least one isolate were produced on only five kudzu plants; however, plants \#41B and \#41C were immune to all three pathogen isolates.

The tendency for kudzu plants to react similarly at individual sites is in line with results of a genetic diversity study conducted by Sun et al. (12) in which they used inter-simple sequence repeat analysis

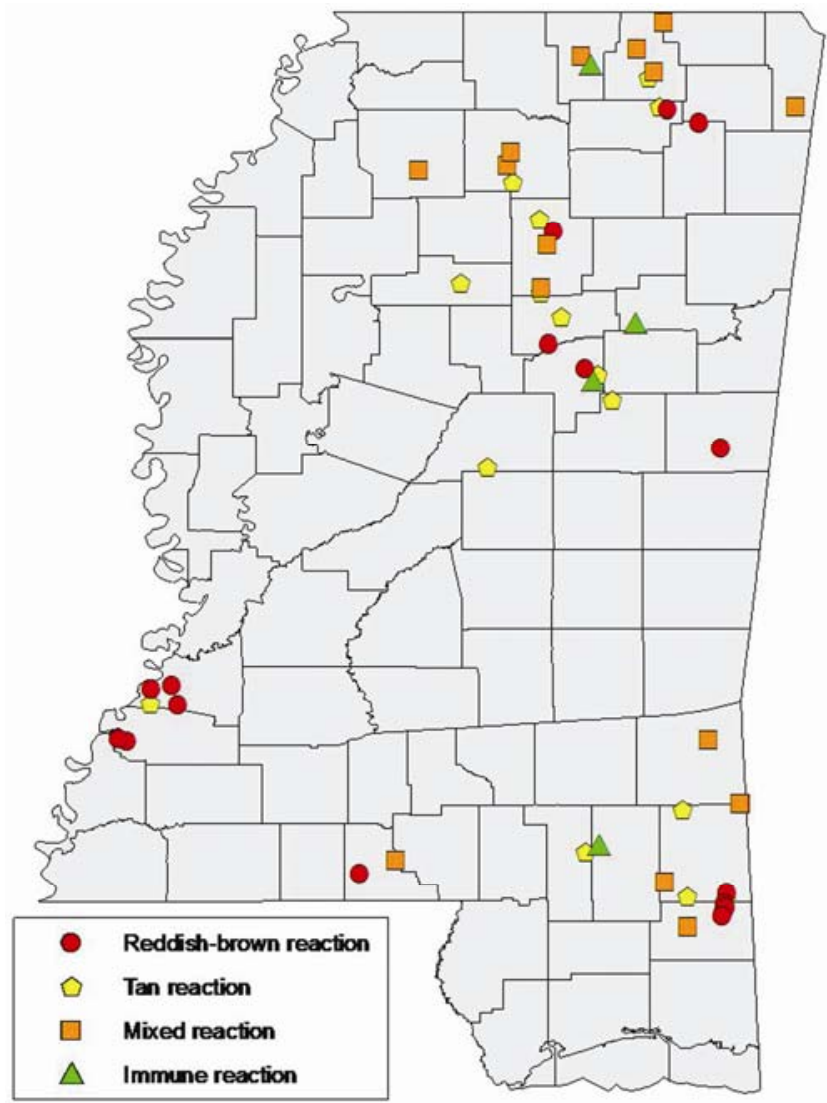

Fig. 2. Locations of sites in Mississippi from which kudzu plants were obtained and their reactions to Phakopsora pachyrhizi isolates based on inoculations in the greenhouse. Mixed reactions indicate that both susceptible tan-colored (TAN) and resistant reddish-brown (RB) lesions developed either on the same plant or on separate plants from the respective locations.
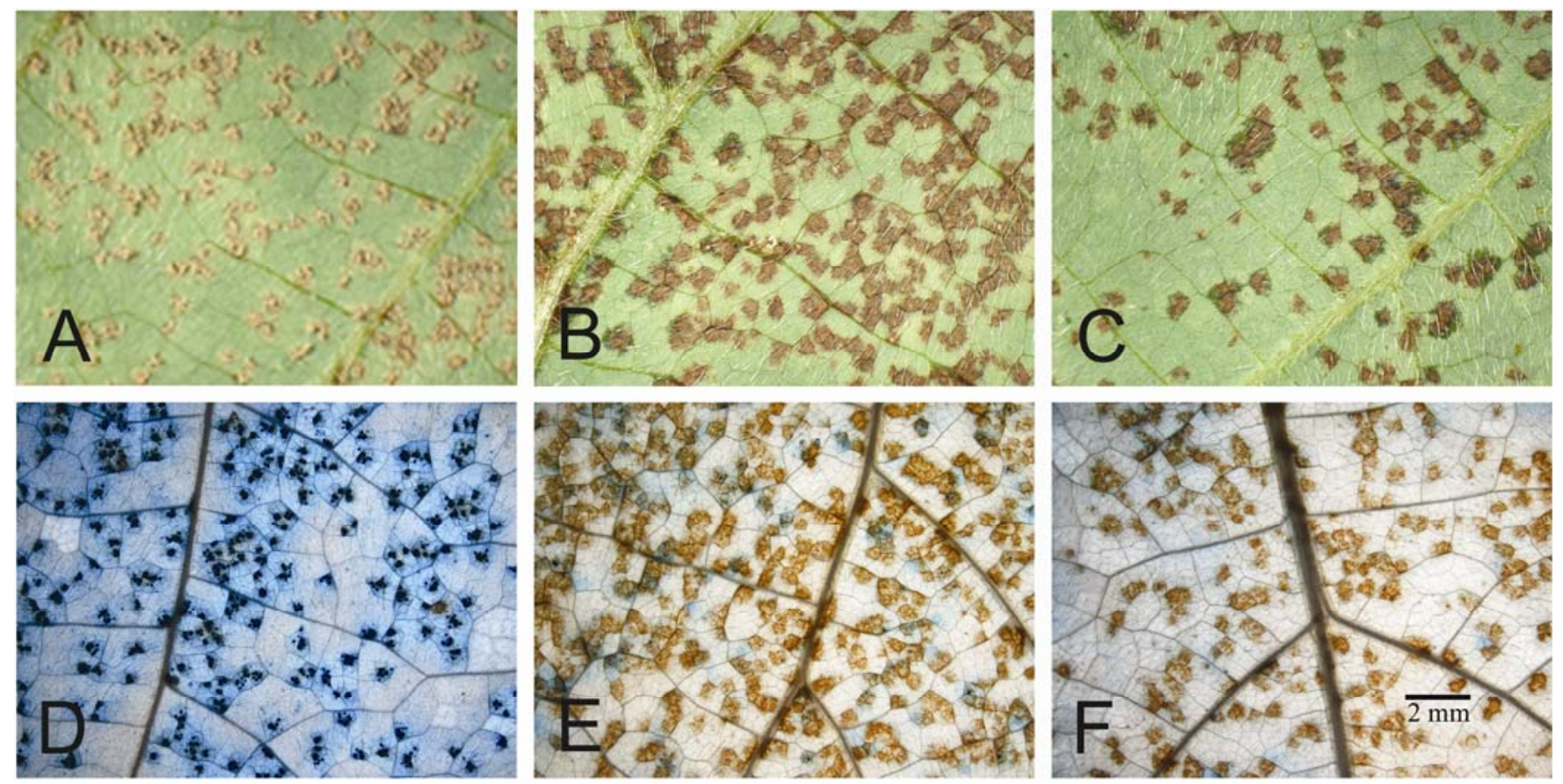

Fig. 1. Susceptible tan-colored (TAN) lesions and resistant reddish-brown (RB) lesions on the same kudzu plant. Upper row shows typical symptoms on leaves, which differentiate biotypes of Phakopsora pachyrhizi. A, TAN lesions with large proportion of lesions sporulating, B, RB lesions with little or no sporulation, and C, RB lesions with water-soaking around individual lesions. Lower row shows typical fungal development within fixed, cleared, and stained leaf tissue from the leaf shown immediately above. D, Uredinia clumps within TAN lesions, E, RB lesions with a few small uredinia, and F, RB lesions with few uredinia in water-soaked lesions. The 2-mm bar applies to the entire figure. 
Table 3. Lesion type reactions on kudzu (Pueraria montana var. lobata) plants inoculated separately with urediniospores of 11 isolates of Phakopsora pachyrhizi $^{\mathrm{a}}$

\begin{tabular}{|c|c|c|c|c|c|c|c|c|c|}
\hline \multirow[b]{2}{*}{ Isolate } & \multicolumn{9}{|c|}{ Plant/ reaction type } \\
\hline & $12 B$ & $17 \mathrm{C}$ & $18 B$ & $18 \mathrm{C}$ & $1 B$ & $14 B$ & $16 B$ & 19A & $25 \mathrm{C}$ \\
\hline Alabama 04-1 & TAN & TAN & TAN & TAN & $\mathrm{RB}$ & $\mathrm{RB}$ & $\mathrm{RB}$ & $\mathrm{RB}$ & $\mathrm{RB}$ \\
\hline Brazil 01-1 & TAN & TAN & TAN & TAN & $\mathrm{RB}$ & $\mathrm{RB}$ & $\mathrm{RB}$ & $\mathrm{RB}$ & $\mathrm{RB}$ \\
\hline Louisiana 04-1 & TAN & TAN & TAN & TAN & $\mathrm{RB}$ & $\mathrm{RB}$ & $\mathrm{RB}$ & $\mathrm{RB}$ & $\mathrm{RB}$ \\
\hline Thailand 01-1 & TAN & TAN & TAN & TAN & IM & $-^{\mathrm{b}}$ & $\mathrm{RB}$ & $\mathrm{RB}$ & $\mathrm{RB}$ \\
\hline Paraguay 01-2 & TAN & TAN & TAN & TAN & $\mathrm{RB}$ & - & $\mathrm{RB}$ & $\mathrm{RB}$ & $\mathrm{RB}$ \\
\hline Zimbabwe01-1 & TAN & TAN & TAN & TAN & $\mathrm{IM}$ & - & $\mathrm{RB}$ & $\mathrm{RB}$ & $\mathrm{RB}$ \\
\hline Taiwan 72-1 & TAN & TAN & $-^{\mathrm{c}}$ & TAN & IM & $\mathrm{RB}$ & $\mathrm{RB}$ & $-^{\mathrm{c}}$ & $\mathrm{RB}$ \\
\hline Taiwan 80-2 & TAN & TAN & - & TAN & $\mathrm{IM}$ & $\mathrm{RB}$ & $\mathrm{RB}$ & - & $\mathrm{RB}$ \\
\hline Vietnam 05-1 & TAN & TAN & - & TAN & $\mathrm{IM}$ & $\mathrm{RB}$ & $\mathrm{RB}$ & - & $\mathrm{RB}$ \\
\hline Columbia 04-1 & TAN & TAN & - & TAN & IM & $\mathrm{RB}$ & $\mathrm{RB}$ & - & $\mathrm{RB}$ \\
\hline India 73-1 & TAN & TAN & - & TAN & IM & $\mathrm{RB}$ & $\mathrm{RB}$ & - & $\mathrm{RB}$ \\
\hline
\end{tabular}

a Plants selected for this study had either all tan-colored (TAN) or all reddish-brown (RB) lesions when inoculated with Alabama 04-1, Brazil 01-1, and Louisiana 04-1 in previous tests. Each isolate was collected from the location and in the year indicated by its designation. (For example, Thailand 01-1 was collected in Thailand in 2001, and was the first isolate of a series. Taiwan 80-2 was collected in Taiwan in 1980, and was the second isolate of a series.)

b Plant 14B replaced 19A partway through experiment, and thus was not inoculated with all isolates.

c Plants 18B and 19A died partway through the experiment, and therefore were not inoculated with all isolates.

to determine genetic diversity in species of Pueraria. They found high genetic diversity among populations but low diversity within populations of $P$. lobata in the United States, and suggested that this might be caused by a combination of multiple introductions of kudzu from Asia followed by high levels of inbreeding within populations.

Although it was not within the scope of our present research to conduct an exhaustive genetic population study, our results did demonstrate the existence of biotypes within the U.S. kudzu population and support observations of Yamaoka et al. (14) that physiological biotypes of $P$. pachyrhizi can be differentiated on kudzu. It is possible that physiological specialization, concomitant with a tendency for plants at some sites to react similarly to all $P$. pachyrhizi isolates, could explain why soybean rust is common on kudzu in some areas and absent in others (W. F. Moore and T. W. Allen, personal observation). Where kudzu can survive winters, the biotypes of $P$. pachyrhizi on kudzu possibly could influence the disease on soybean. Because many plants inoculated with Alabama 04-1 (41\%), Brazil 01-1 (33\%), or Louisiana $04-1$ (31\%) produced no or extremely low numbers of uredinia, and approximately $25 \%$ produced no or extremely low numbers of uredinia for all three isolates, it was apparent that there are situations in which kudzu might not contribute to disease increase or spread.

Average numbers of uredinia per lesion and average uredinium diameters are quantitative measurements that correlate with the ability of $P$. pachyrhizi to sporulate on a host (2). As such, they could be used to measure susceptibility or resistance to soybean rust. Although lesion densities on kudzu leaves with TAN reactions were significantly higher than on leaves with RB reactions, this observation could have been an artifact related to the subjective manner (i.e., ratings) in which lesion densities were determined. In order to determine with certainty any association of TAN reactions with lesion density, individual lesions would have to be counted on plants.

Based on reports during the last several years of soybean rust on kudzu in the southern United States during winter and early spring months, it is probable that $P$. pachyrhizi survives in isolated pockets (USDA Public PIPE Website, www.sbrusa. net/). In these areas, and areas where the pathogen subsequently moves, the susceptibility of the kudzu vegetation, and that of other possible hosts, to the prevalent biotypes of $P$. pachyrhizi could influence disease development on soybean.

In addition to the ability of the pathogen to survive winters on kudzu and other hosts, economic losses to soybean will depend on the suitability of the environment during the growing season for rust buildup and spread. Consequently, we are conducting research to determine how temperature and moisture affect soybean rust development in the United States and anticipate that when all information is assimilated, we will have a better understanding of the future of soybean rust in the United States.

\section{ACKNOWLEDGMENTS}

We thank Haley Tipton and Torri Hancock for excellent technical assistance during the study, Mitt Wardlaw for his valuable assistance with determining GPS coordinates, and William Bruckart for many helpful suggestions during preparation of the manuscript. We also thank J. T. Yorinori, R. D. Frederick, and R. W. Schneider for providing isolates of $P$. pachyrhizi.

\section{LITERATURE CITED}

1. Bonde, M. R., Melching, J. S., and Bromfield, K. R. 1976. Histology of the suscept-pathogen relationship between Glycine max and Phakopsora pachyrhizi, the cause of soybean rust. Phytopathology 66:1290-1294.

2. Bonde, M. R., Nester, S. E., Austin, C. N., Stone, C. L., Frederick, R. D., Hartman, G. L., and Miles, M. R. 2006. Evaluation of virulence of Phakopsora pachyrhizi and P. meibomiae isolates. Plant Dis. 90:708-716.

3. Bonde, M. R., Nester, S. E., Berner, D. K.,
Frederick, R. D., Moore, W. F., and Little, S. 2008. Comparative susceptibilities of legume species to infection by Phakopsora pachyrhizi. Plant Dis. 92:30-36.

4. Britton, K. O., Orr, D., and Sun, J. 2002. Kudzu. In: Biological Control of Invasive Plants in the Eastern United States. R. van Driesche, B. Blossey, M. Hoddle, S. Lyon, and R. Reardon, eds. USDA Forest Service, publ. no. FHTET-2002-04.

5. Bromfield, K. R. 1984. Soybean Rust. Monogr. No. 11. American Phytopathological Society, St. Paul, MN.

6. Bromfield, K. R., Melching, J. S., and Kingsolver, C. H. 1980. Virulence and aggressiveness of Phakopsora pachyrhizi isolates causing soybean rust. Phytopathology 70:17-21.

7. Cherry, E., and Peet, C. E. 1966. An efficient device for the rapid collection of fungal spores from infected plants. Phytopathology 56:11021103.

8. Melching, J. S., Bromfield, K. R., and Kingsolver, C. H. 1979. Infection, colonization, and urediniospore production on Wayne soybean by four cultures of Phakopsora pachyrhizi, the cause of soybean rust. Phytopathology 69:1262-1265.

9. Melching, J. S., Bromfield, K. R., and Kingsolver, C. H. 1983. The pathogen containmen facility at Frederick, Maryland. Plant Dis. 67:717-722.

10. Melching, J. S., Dowler, W. M., Koogle, D. L., and Royer, M. H. 1989. Effects of duration, frequency, and temperature of leaf wetness periods on soybean rust. Plant Dis. 73:117-122.

11. Schneider, R. W., Hollier, C. A., Whitam, H K., Palm, M. E., McKemy, J. M., Hernandez, J. R., Levy, L., and DeVries-Paterson, R. 2005. First report of soybean rust caused by Phakopsora pachyrhizi in the continental United States. Plant Dis. 89:774.

12. Sun, J. H., Li, Z.-C., Jewett, D. K., Britton, K. O., Ye, W. H., and Ge, X.-J. 2005. Genetic diversity of Pueraria lobata (kudzu) and closely related taxa as revealed by inter-simple sequence repeat analysis. Eur. Weed Res. Soc. Weed Res. 45:255-260.

13. Susko, D. J., Mueller, J. P., and Spears, J. F. 2001. An evaluation of methods for breaking seed dormancy in kudzu (Pueraria lobata). Can. J. Bot. 79:197-203.

14. Yamaoka, Y., Fujiwara, Y., Kakishima, M., Katsuya, K., Yamada, K., and Hagiwara, H. 2002. Pathogenic races of Phakopsora pachyrhizi on soybean and wild host plants collected in Japan. J. Gen. Plant Pathol. 68:52-56. 